Article

\title{
Friction Stir Spot Welding with Additional Bonding of Thick Sheet Aluminum Joints
}

\author{
Marcel Hatzky *, Antonia Frank and Stefan Böhm \\ Department for Cutting and Joining Manufacturing Processes, University of Kassel, Kurt Wolters Str. 3, \\ 34125 Kassel, Germany \\ * Correspondence: m.hatzky@uni-kassel.de; Tel.: +49-561-804-7354
}

Received: 14 June 2019; Accepted: 27 June 2019; Published: 28 June 2019

\begin{abstract}
The high-strength aluminum alloys offer great potential for realizing lightweight constructions in car body construction. However, the use of aluminum alloys increases the overall thickness of the material, which poses new challenges for potential joining processes. This paper examines a process combination of friction stir spot welding (FSSW) and bonding for $4 \mathrm{~mm}$ EN AW 6082-T6 sheets. For the investigations, adhesive or glass beads were applied between the joining components and then the sheets were welded using FSSW. The analysis shows that the adhesive and the glass beads have a very small influence on the joint formation. The use of glass beads in FSSW with bonding is recommended because less adhesive is displaced from the joint area, which increases the joint strength. The target of obtaining high weld spot strengths without strength-reducing adhesive burn-off could not be achieved because a certain residence time is necessary to form a weld spot with high strength at this sheet thickness in order to sufficiently plasticize the material. Adhesive burn-up cannot be completely avoided. For this reason, it is necessary to weigh up which characteristics are required for the specific application and adjust the welding parameters accordingly.
\end{abstract}

Keywords: friction stir spot welding; bonding; thick sheet; aluminum alloy; hybrid connection

\section{Introduction}

Friction stir welding with adhesive bonding (FSSBW) is a hybrid joining process consisting of FSSW and adhesive bonding. Hybrid joining is generally understood to mean the combination of two or more elementary joining processes with the aim of exploiting the advantages of the individual joining processes and compensating for the disadvantages. With the help of suitable dimensioning methods, properties can be achieved that are greater than the sum of the individual properties [1]. In practice, combinations of bonding and a (mechanical) spot joining process are frequently used, whereby the spot joining process serves to fix the joining partner during adhesive curing. These process combinations result in increased strength, stiffness, and vibration resistance of the sheet metal joint. In addition, punctiform joining processes can support the adhesive layer during peeling and static long-term loading [1]. The process combinations of bonding with resistance spot welding, clinching, or riveting are already successfully used in thin sheet metal [2]. For thick sheet metal joints, however, the processes cannot be successfully applied. Resistance spot welding of thick sheets requires higher current strengths and electrode forces, which can lead to metallurgical peculiarities in the form of cracks and pores [3,4]. Insufficient displacement of adhesives can lead to spattering, which contaminates the component surface and reduces reproducibility [5]. In the case of clinching thick sheet metals, the high forces required have a negative effect, which can lead to uncontrolled bending (component distortion) of the sheet metal pairs, thus promoting gap formation and inadequate seam sealing. The latter increasing the risk of corrosion cracking [6]. 
Due to its process advantages, the FSSW represents an alternative joining process for bonding, but there are only a few studies available for aluminum thin sheets, however, these are promising. Chowdhury et al. investigated the tensile shear strength and failure behavior of friction stir welded $2 \mathrm{~mm}$ thick AZ31B and AA5754 magnesium or aluminum sheets. The adhesive Terokal 5089 (one-component metal adhesive, hot house curing, based on epoxy resin [7]) was applied to the overlap joint of the dimensions $35 \times 35 \mathrm{~mm}^{2}$ and cured at $170{ }^{\circ} \mathrm{C}$ for $20 \mathrm{~min}$ before the FSSW. The comparison between the FSSBW Al/Mg or Mg/Al (upper sheet/lower sheet) and RRPS Al/Mg joints showed that both FSSBW joints had higher tensile shear strengths and considerably longer fatigue life than the Al/Mg RRPS joint [8]. Ding et al. were also able to show in their study of the FSSBW of $3 \mathrm{~mm}$ thick AZ31 magnesium sheets, with an overlap area of $50 \times 50 \mathrm{~mm}^{2}$ that the tensile shear strength of the FSSBW joints is significantly higher than that of the bonded or only friction-welded joints. In addition, they were able to demonstrate that the adhesive has only a minor influence on the joint formation and the microstructure. Nevertheless, it is made clear that the optimum parameters for the joining partners must be determined in order to exploit the properties of this hybrid joining process $[9,10]$.

There are currently no publications on the FSSBW of thick sheet aluminum joints, which provides an incentive for research in this area.

\section{Materials and Methods}

In this paper, the aluminum alloy EN AW 6082-T6 is used for the FSSBW tests. This material belongs to the hardenable AlMgSi wrought alloys and is solution annealed, quenched, and artificially aged, which is characterized by the designation T6. In general, the materials of the 6XXX series are characterized by high fracture toughness, good corrosion resistance, and good cold formability. EN AW 6082-T6 has a medium strength, which is higher than the strength of EN AW 6061, as well as very good weldability, and corrosion resistance [11]. This alloy is mainly used in car body construction, shipbuilding, and rail vehicle construction. The chemical composition and physical and mechanical properties of this alloy can be found in Tables 1 and 2.

Table 1. Chemical composition of EN AW 6082-T6 aluminum alloy [12].

\begin{tabular}{ccccccccccc}
\hline Element & $\mathbf{S i}$ & $\mathbf{F e}$ & $\mathbf{C u}$ & $\mathbf{M n}$ & $\mathbf{M g}$ & $\mathbf{C r}$ & $\mathbf{Z n}$ & $\mathbf{T i}$ & Remaining & Al \\
\hline Percentage $(\%)$ & $0.7-1.3$ & 0.5 & 0.1 & $0.4-1.0$ & $0.6-1.2$ & 0.25 & 0.2 & 0.1 & $0.5-0.15$ & Remaining \\
\hline
\end{tabular}

Table 2. Physical and mechanical properties of the EN AW 6082-T6 aluminum alloy [12].

\begin{tabular}{cc}
\hline Physical and Mechanical Properties & EN AW 6082-T6 \\
\hline Density $\left(\mathrm{g} / \mathrm{cm}^{3}\right)$ & 2.7 \\
Melting temperature $\left({ }^{\circ} \mathrm{C}\right)$ & $585-650$ \\
Tensile strength $R \mathrm{~m}\left(\mathrm{~N} / \mathrm{mm}^{2}\right)$ & 310 \\
Yield strength $R \mathrm{p} 0.2\left(\mathrm{~N} / \mathrm{mm}^{2}\right)$ & 260 \\
Elongation at break A $(\%)$ & 10 \\
Thermal conductivity $(\mathrm{W} / \mathrm{mK})$ & $170-220$ \\
Hardness $(\mathrm{HB})$ & 94 \\
\hline
\end{tabular}

The sample geometry and welding configuration can be seen in Figure 1. This is an overlap joint designed in accordance with DIN EN ISO 14273. This standard deals with the destructive testing of resistance, roll seam, and projection welded joints with embossed projections. 


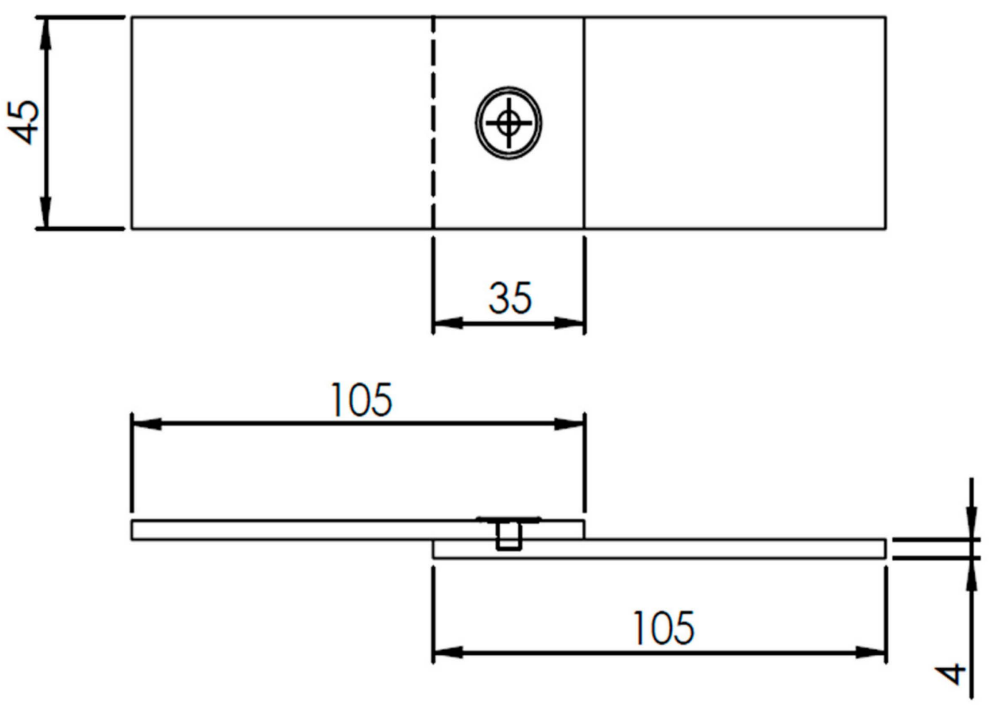

Figure 1. Sample geometry and welded construction, unit: $\mathrm{mm}$.

A structural adhesive is used as the adhesive for the investigations. Betamate structural adhesives are used in automotive production, especially in body-in-white construction, for example to join various body components or in combination with welding. In addition, these adhesives have very good adhesion to the metals, whereby the surfaces do not have to be primed or degreased [13]. The Betamate $1460 \mathrm{~N}$ adhesive used is a 1-component structural adhesive based on epoxy resin, which cures warm. In addition, this adhesive is characterized by high temperature and break resistance as well as a sealing effect to protect the weld spot from corrosion. The mechanical-technological characteristic values can be found in Table 3.

Table 3. Mechanical-technological characteristics of the adhesive Betamate $1460 \mathrm{~N}$.

\begin{tabular}{cc}
\hline Designation & Betamate 1460 N \\
\hline Type & $1-\mathrm{K}$ \\
Base & Epoxidharz \\
Colour & Violett \\
Viscosity at $45^{\circ} \mathrm{C}$ & 75 Pa-s \\
Curing condition & 30 min at $180{ }^{\circ} \mathrm{C}$ \\
Tensile shear strength (MPa) (adhesive area: & 27 \\
$25 \mathrm{~mm} \times 10 \mathrm{~mm}$ adhesive layer thickness: $0.2 \mathrm{~mm})$ & 6 \\
Elongation $(\%)$ & 6 \\
\hline
\end{tabular}

\section{Further Information on the Methods}

To record the temperature profile around the end hole, the upper samples were drilled vertically and horizontally with three $\varnothing 1.3 \mathrm{~mm}$ through holes each for type $\mathrm{K}$ thermocouples. The distance between the drill centers is $2 \mathrm{~mm}$. The measuring technique, which has a variable recording rate, can record data in 3 channels per measurement.

The tensile shear tests are performed with a Zwick/Roell Z100 universal tensile testing machine (ZwickRoell GmbH \& Co. KG, Ulm, Germany) with positioning accuracy of $\pm 2 \mu \mathrm{m}$ and a load cell up to $30 \mathrm{kN}$. The measurement is carried out at a test speed of $10 \mathrm{~mm} / \mathrm{min}$, whereby the tensile force and elongation are recorded with a step width of $10 \mu \mathrm{m}$. As there is currently no test standard for friction stir welded specimens, the procedure is based on DIN EN ISO 14273.

The metallographic examination is performed with the Leica Z16 APO A light macroscope (Leica Mikrosysteme Vertrieb GmbH, Wetzlar, Germany). The evaluation is performed with the Leica Application Suite user software (Leica Application Suite 4.9.0, Leica Mikrosysteme Vertrieb GmbH, Wetzlar, Germany). 


\section{Results}

In the following test series, the hybrid manufacturing process from FSSW and bonding is investigated. The aim is to realize high weld spot strengths without strength-reducing adhesive burn-off in order to be able to exploit the positive mechanical properties of this hybrid process. From previous investigations, the welding stud geometry GewN (M5 thread with three spiral grooves) and the shoulder SS (shoulder with worm) emerged as optimal tools. Additionally, the optimum speed for the FSSW tests has already been worked out, which is now also used in the FSSBW. For the following test series, therefore, only the dwell time is varied. Based on preliminary investigations of the temperature behavior, damage to the adhesive layer is to be expected with increasing residence time.

Figure 2 shows the temperature curve at the welding stud for the four residence times. All samples show a similar heating and cooling behavior, but the maximum temperature rises up to $4 \mathrm{~s}$ dwell time. From 4 to $6 \mathrm{~s}$, no further increase of the maximum temperature can be recorded, which has already been shown in the tests for parameter determination. However, this diagram can be used to explain why the samples with a residence time of $6 \mathrm{~s}$ were noticeably warmer, as the samples were kept at the maximum temperature for longer due to the longer residence time.

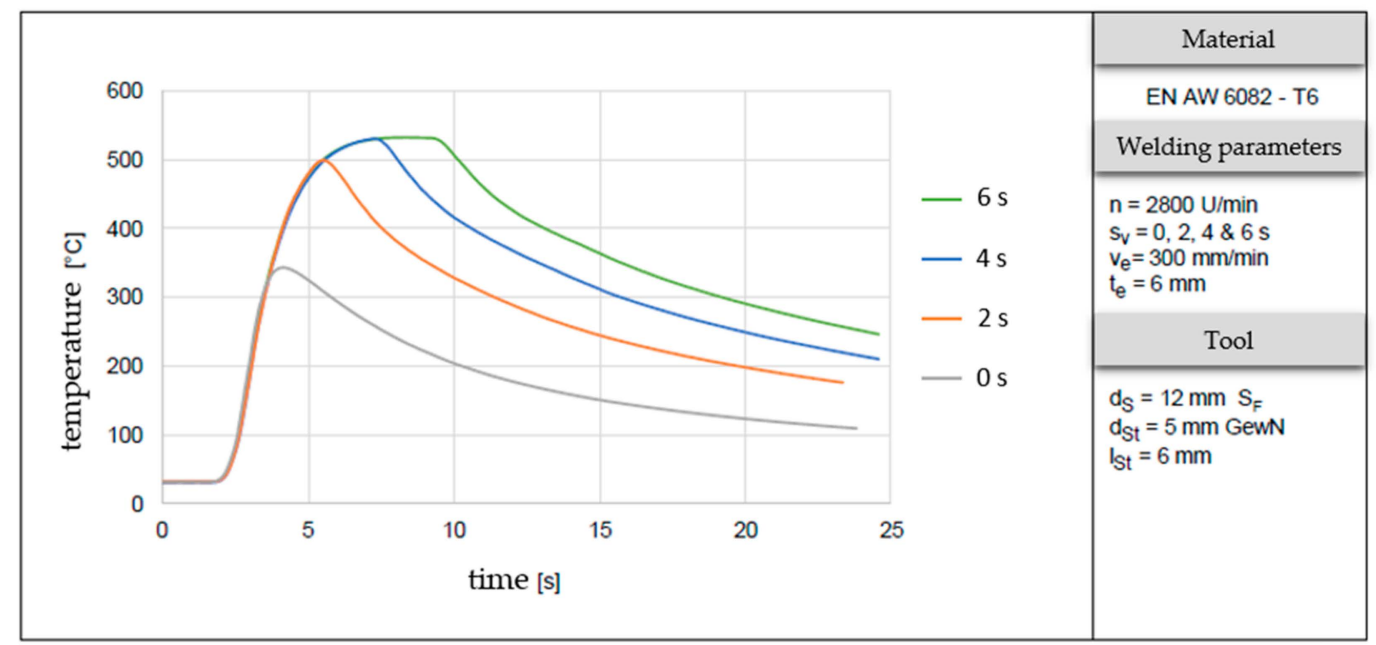

Figure 2. Temperature curve at welding pin at $0,2,4$, and $6 \mathrm{~s}$ dwell time.

In the FSSBW study, the influence of glass beads on strength and material flow should be considered, which is why tests with and without glass beads are carried out. The glass beads have a diameter of $0.25 \mathrm{~mm}$. Table 4 shows the experimental design for the FSSBW study.

Table 4. Friction stir welding with adhesive bonding (FSSBW) experimental plan.

\begin{tabular}{|c|c|c|c|c|c|c|c|c|}
\hline Number & 1 & 2 & 3 & 4 & 5 & 6 & 7 & 8 \\
\hline Shoulder & \multicolumn{8}{|c|}{ SS } \\
\hline Pin geometry & \multicolumn{8}{|c|}{ GewN } \\
\hline Pin length (mm) & \multicolumn{8}{|c|}{6} \\
\hline Speed (rpm) & \multicolumn{8}{|c|}{2800} \\
\hline Immersion speed $(\mathrm{mm} / \mathrm{min})$ & \multicolumn{8}{|c|}{300} \\
\hline Immersion depth (mm) & \multicolumn{8}{|c|}{6.2} \\
\hline Dwell time (s) & 0 & 2 & 4 & 6 & 0 & 2 & 4 & 6 \\
\hline Glass beads & \multicolumn{5}{|c|}{ Without } & \multicolumn{3}{|c|}{ With } \\
\hline
\end{tabular}


The results of the tensile shear test of the FSSBW specimens with and without glass beads are shown in Figure 3 and compared with the results of the purely friction stir welded and purely bonded specimens. On the one hand, it can be observed that the FSSBW specimens with glass beads achieve higher tensile shear forces than the FSSBW specimens without glass beads. The reason for this is probably the displacement of the adhesive from the adhesive joint. To verify this assumption, the cross sections and fracture patterns are examined below. For all FSSBW specimens, a greater dispersion of the tensile force can be observed compared to the FSSW specimens, presumably caused by the different characteristics of the adhesive layer.

If the tensile strength of the purely bonded and purely friction-welded specimens is compared, the weld points achieve higher strengths. With a maximum tensile force of $11.7 \mathrm{kN}$ and a weld spot area of $93.5 \mathrm{~mm}^{2}$, the tensile strength is $125 \mathrm{MPa}$. The purely bonded specimens withstand a tensile force of $32.9 \mathrm{kN}$ with an adhesive surface of $1575 \mathrm{~mm}^{2}$, which corresponds to a tensile strength of 20.9 MPa. On the other hand, all FSSBW specimens have a lower tensile force than the purely bonded specimens. In addition, the shear forces decrease with increasing residence time, which can probably be attributed to the strength-reducing adhesive burn-up. The difference in shear forces between the FSSW and FSSBW specimens also decreases with increasing residence time, suggesting that the adhesive layer contributes less to the overall strength of the joint. With a residence time of $0 \mathrm{~s}$, on the other hand, it can be assumed that the high joint strength is almost exclusively based on the adhesive strength, since the FSSW specimens have significantly lower weld spot strengths due to the lower heat input and thus insufficient plasticization of the material.

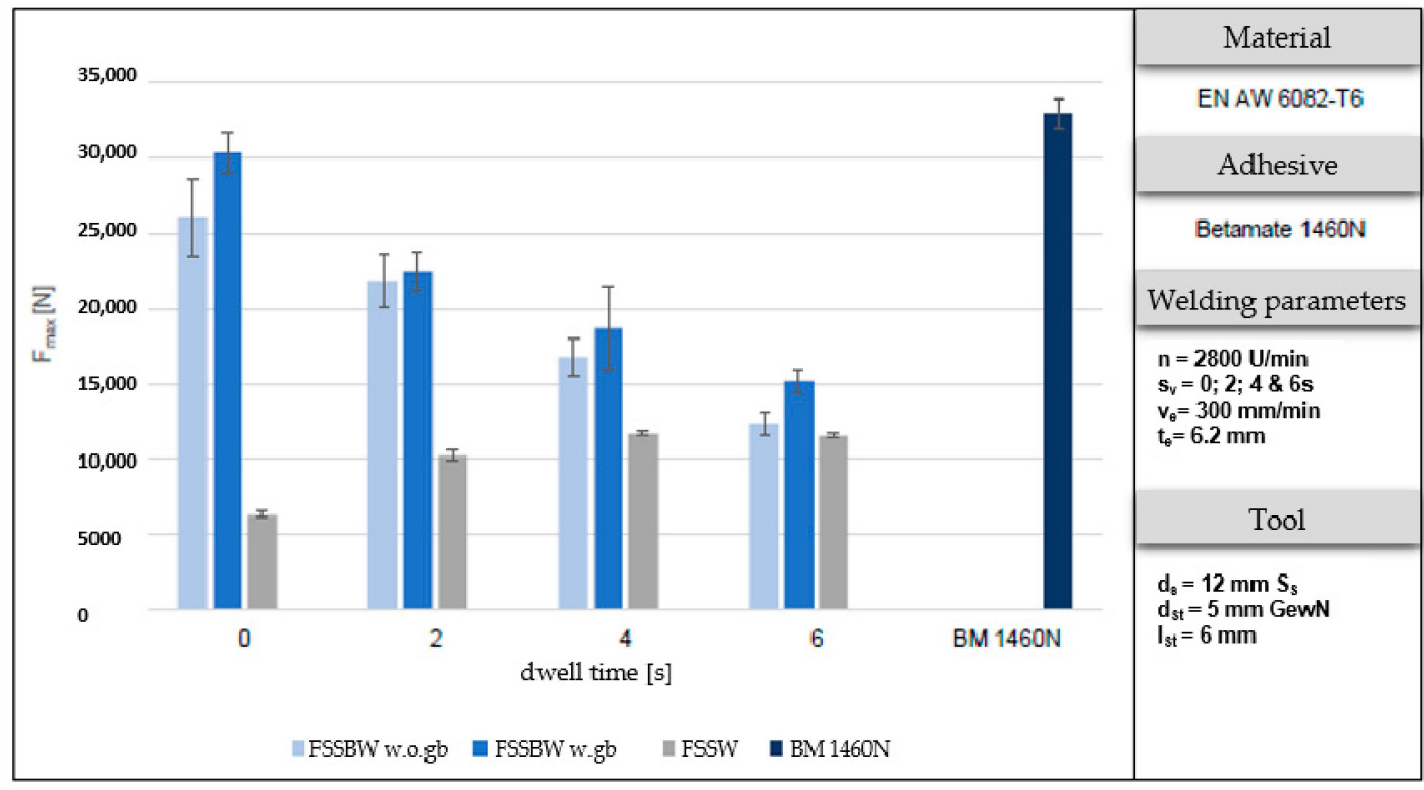

Figure 3. Comparison of the averaged maximum tensile shear forces between friction stir spot welding (FSSW), FSSBW, and adhesive bonding.

Figure 4 shows the fracture patterns of the RRPSK specimens with and without glass beads at a residence time of $4 \mathrm{~s}$. The specimens without glass beads have a smaller residual amount of adhesive in the overlap area. When the tool is immersed, forces of more than $20 \mathrm{kN}$ occur in the axial direction. When the tool is immersed, the glass beads prevent large parts of the adhesive from being displaced from the adhesive joint. Nevertheless, the adhesive has been displaced from the adhesive joint in these samples as well, which is indicated by the fracture pattern. On the one hand, the pattern is created by the displacement of the adhesive due to the application of force and the subsequent contraction of the adhesive during relief. Since the adhesive has already been pressed out of the adhesive joint, it can no longer be completely filled. On the other hand, the adhesive is decomposed and reduced in quantity because of the heat input. Due to the residual moisture in the adhesive, gases can be produced during 
heating, which can also contribute to the formation of this pattern. Additionally, the adhesive layer is damaged around the welding point.

No difference is visible regarding the type of failure of the weld spot. Both specimens show a mixed fracture with about half of the spot weld being pulled out. This type of failure also occurs with the purely friction stir welded specimens, so that it can be stated that the adhesive has no influence on the failure behavior of the weld spot. Whether the glass beads and the adhesive have an influence on the RZ can be better assessed on the basis of the cross-section images. Both specimens show a cohesion fracture. This is a sign of a high-quality bond and indicates a good bond between the joining part material EN AW 6082-T6 and the adhesive Betamate $1460 \mathrm{~N}$. The bond between the two materials is also good.

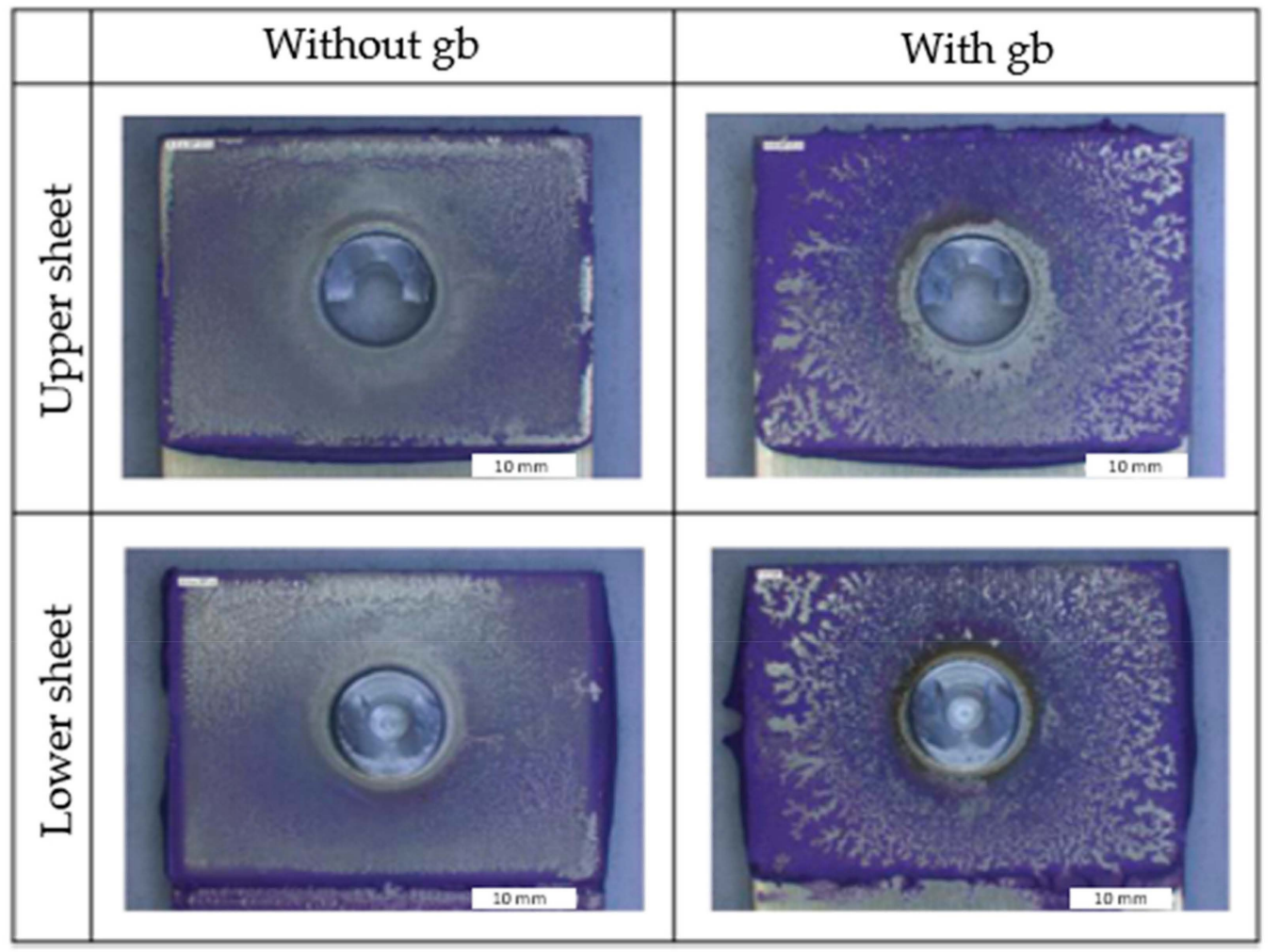

Figure 4. Surface of FSSBW specimens with and without glass beads at a residence time of $4 \mathrm{~s}$ after fracture.

The cross-section images in Figure 5 confirm that the adhesive is largely displaced from the adhesive joint in the specimens without glass beads. In the glass bead specimen, on the other hand, a defined adhesive layer is visible immediately behind the shoulder impression. The displacement of the adhesive below the shoulder diameter confirms that the adhesive has no effect on the material flow and the stirring zone. The geometry and shape of the stirring zone of the FSSBW samples are similar to those of the FSSW samples. Under the complete shoulder impression, these samples show a stirring zone and a steep hook running along the stirring zone to the outer edge of the shoulder impression (see sample S2 in Figure 5). A closer look at the FSSBW cross sections also reveals the onion rings. Complete glass beads, on the other hand, are not visible in the RZ. These are probably broken into fine fragments around the welding spot due to the high axial forces or are simply not in the plane of the cut. 

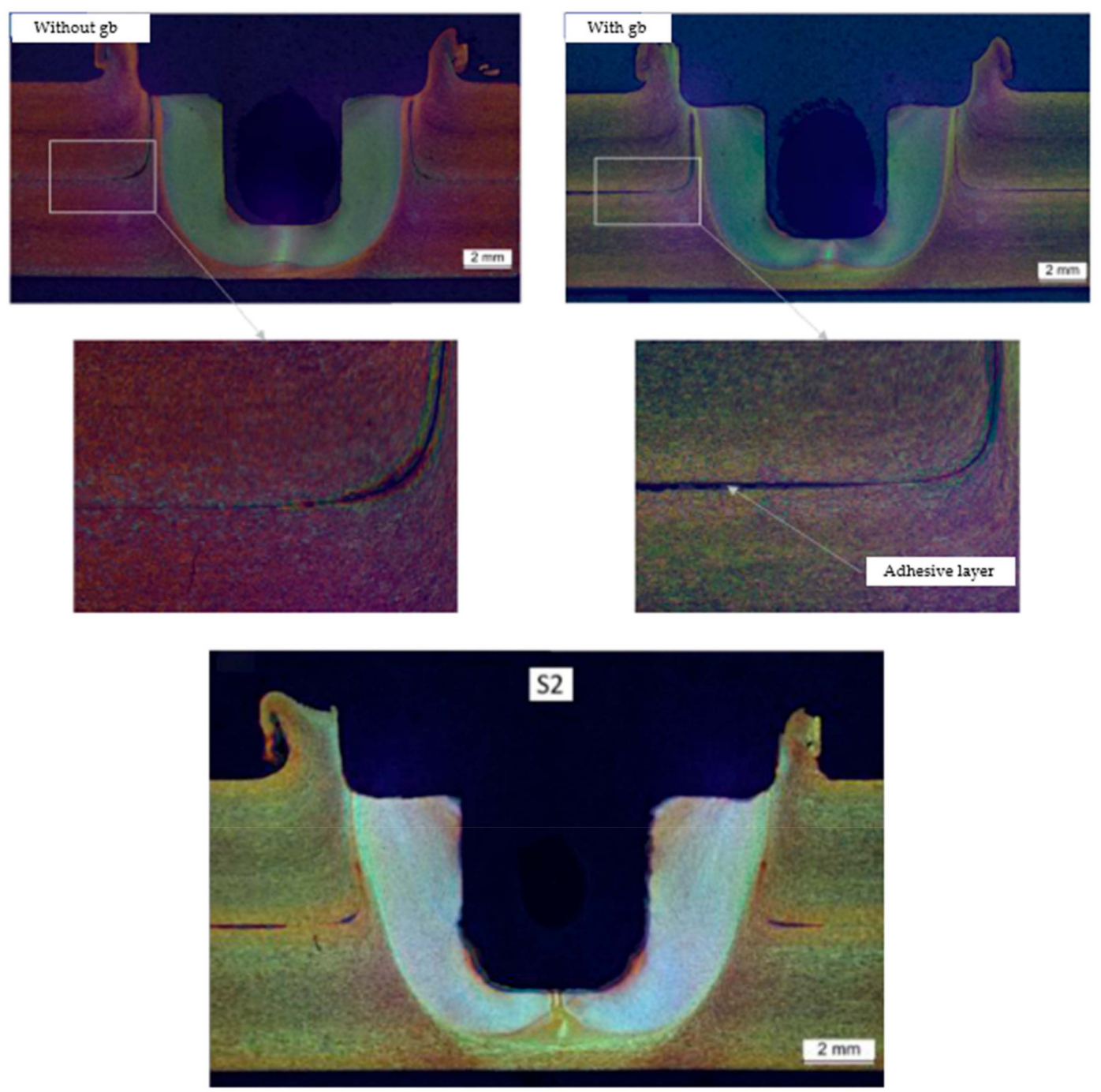

Figure 5. Cross section images of FSSBW specimens with and without glass beads at a residence time of $4 \mathrm{~s}$ and a cross-section image of FSSW specimen.

The shear forces of the FSSBW specimens decrease by almost $50 \%$ with increasing residence time. The fracture patterns of the FSSBW specimens with glass beads are shown in ascending residence time in Figure 6. The temperature runs for this area were modelled from the data of the thermocouple in the welding stud and the three thermocouples each placed around the welding spot and graphically shown in Figure 6. For this purpose, the local maximum temperature values of the sensors during the welding process were used for the different dwell times. Since only punctual values were recorded, this distribution has to be considered qualitatively. While at a residence time of $0 \mathrm{~s}$ no adhesive burn-off can be observed, but only a displacement of the adhesive around the weld spot, increasing adhesive burn-off can be observed at a residence time of $2 \mathrm{~s}$ and longer. Adhesive burn-off is shown by the yellow-brown discoloration around the weld spot and is greatest at the longest dwell time. This result is not surprising when the temperature curves in Figure 6 are considered. 

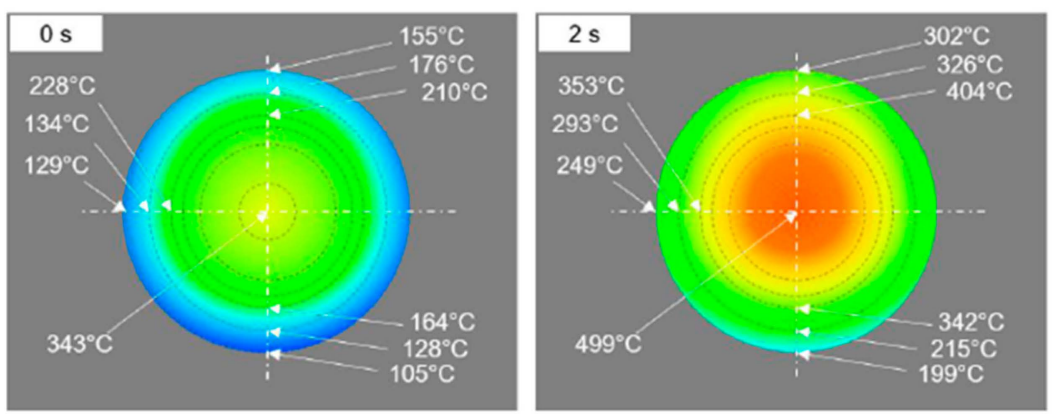

Temperature
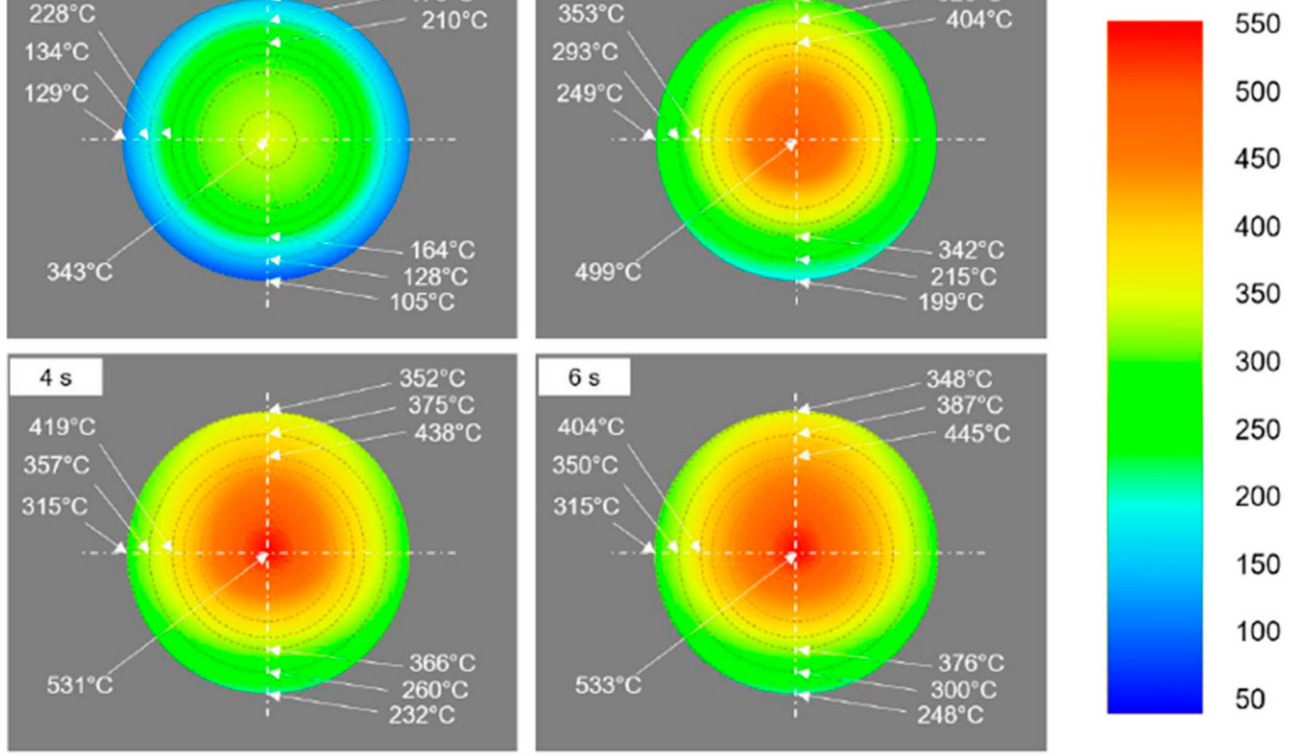

450

400

350

300

250

200

150

100

50

Figure 6. Temperature curve around the welding spot at different dwell times.

The samples at $4 \mathrm{~s}$ and $6 \mathrm{~s}$ reach almost identical maximum temperatures at the welding stud and show a similar temperature distribution, but the heat input at $6 \mathrm{~s}$ is higher. At a residence time of $0 \mathrm{~s}$, temperatures of around $200{ }^{\circ} \mathrm{C}$ occur at the internal sensors, which does not damage the adhesive. As the residence time increases, temperatures more than $350{ }^{\circ} \mathrm{C}$ or $430{ }^{\circ} \mathrm{C}$ are recorded, which damage the adhesive in this area.

Based on the fracture pattern of the specimen (Figure 7) with a residence time of $0 \mathrm{~s}$, it can be confirmed that the high joint strength is based almost exclusively on the adhesive strength, since the adhesive layer is hardly damaged, and the weld spot fails in the shear fracture, which is attributable to the low heat input. With increasing residence time, the fracture behavior changes to a mixed fracture with tearing of up to about half of the weld spot.

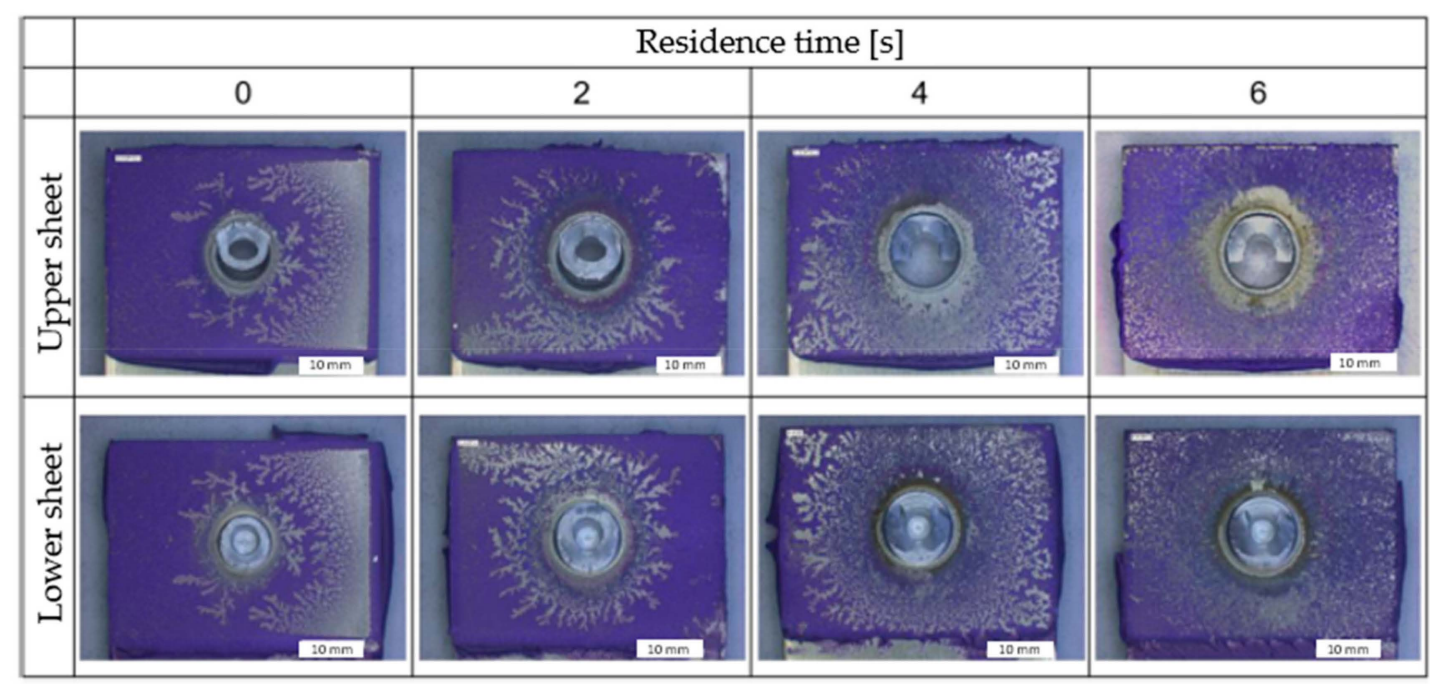

Figure 7. Surface of FSSBW specimens with glass beads at 0, 2, 4, and 6 s residence time after fracture.

Figure 8 shows a force-elongation diagram of the FSSBW specimens with glass beads and the purely bonded specimen. It becomes clear that with the FSSBW, the elongation at break can be increased considerably. The increase is over $150 \%$. Furthermore, the time-delayed failure of the weld spot can be observed based on this diagram. After the maximum force has been reached by the adhesive 
layer, the tensile force drops abruptly. There, the weld spot takes hold and considerably increases the elongation at break. Even though the maximum tensile force decreases steadily with increasing residence time, the specimens achieve similar elongations, which is attributable to the changed fracture behavior. The weld spot, thus, contributes to an increased energy absorption, which is particularly desirable for car body components. A high plastic elongation is advantageous for crash-relevant components, as the impact energy is absorbed more efficiently, and less acceleration change occurs. A further advantage is that safety-relevant components deform plastically before final failure and are therefore easy to identify optically.

However, the selection of the optimum parameters must be adapted to the specific application. The welding parameters of the test series (dwell time $2 \mathrm{~s}$ ) are characterized by good weld spot formation and justifiable heat input, since a minimum input of heat is necessary to form a large stirring zone and thus achieve high weld spot strength with simultaneous low adhesive layer damage. Although the weld spot strength increases by $14 \%$ from $2 \mathrm{~s}$ to $4 \mathrm{~s}$ dwell time (see Figure 3), the overall strength of the hybrid joint decreases due to adhesive burn-up. The tensile strength is highest at $0 \mathrm{~s}$, but this is mainly due to the adhesive layer and not to the weld spot. This is particularly disadvantageous with cyclically loaded components.

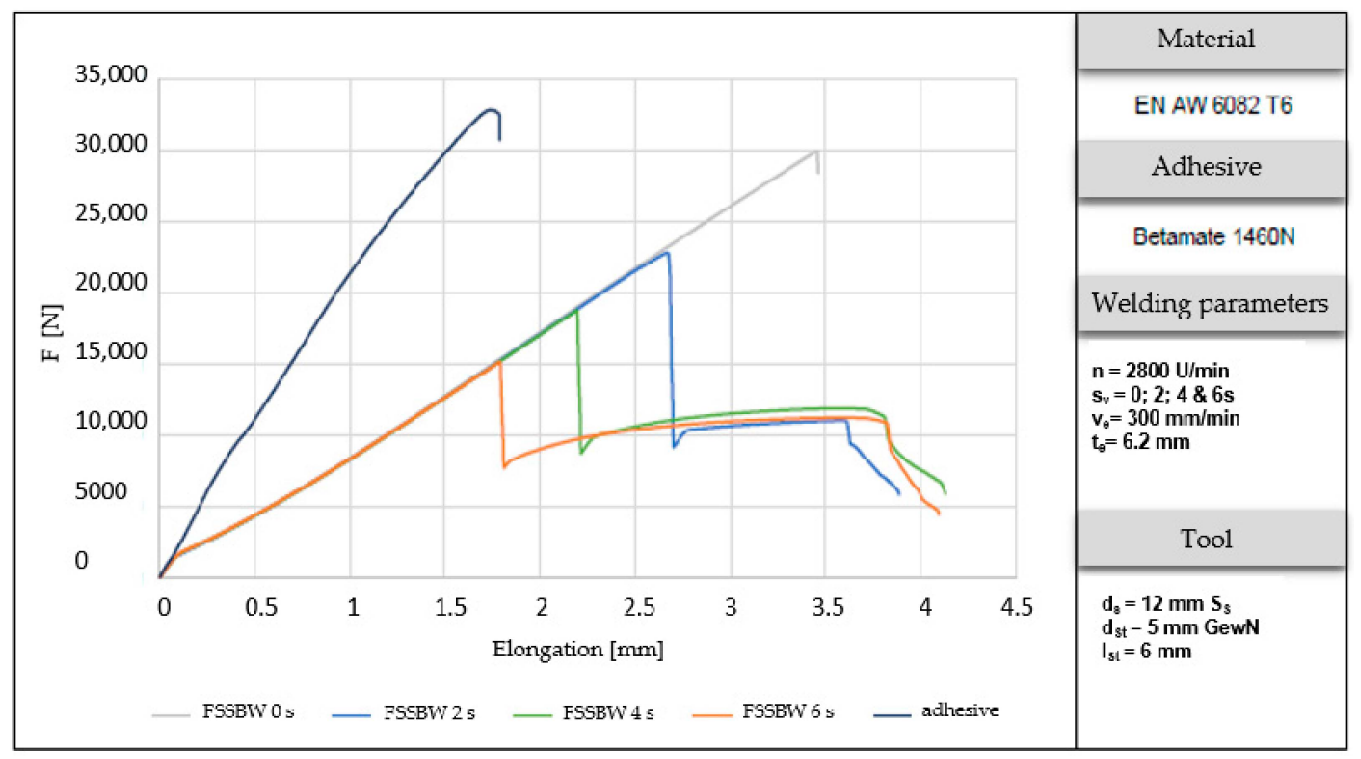

Figure 8. Force-elongation diagram.

In summary, it can be said that the adhesive has no influence on the material flow and the type of failure. In addition, the use of glass beads is recommended as the glass beads reduce the displacement of the adhesive from the adhesive joint. The FSSBW specimens show both high shear forces and high plastic deformability and are suitable for the application of crash-relevant components. Only after the complete failure of the adhesive layer does the spot weld failure occur, whereby the spot weld serves as additional protection. However, it is important to consider the specific application and to adapt the parameters to it.

\section{Discussion}

The evaluation of the FSSBW tests shows that the adhesive and the glass beads have a very small influence on the joint formation, since the adhesive is displaced from the joint zone below the shoulder. This result is in line with the research of Ding et al. who could prove that the adhesive has only a small influence on the joint formation and the microstructure $[9,10]$.

However, Ding et al. were able to achieve higher tensile shear forces with the FSSBW than with the purely bonded or only friction-welded joints. This effect could not be observed in the present 
investigations. With the FSSBW, lower tensile shear forces were achieved in comparison to the purely bonded joints. This is probably due to the type of adhesive used. While in Ding et al. the purely bonded specimens withstand tensile shear forces around the friction spot welded specimens, in this work, the tensile shear forces of the purely bonded specimens exceed those of the FSSW specimens by more than $170 \%$, since the Betamate $1460 \mathrm{~N}$ adhesive has a high internal strength.

The decrease in tensile shear forces with increasing residence time can be explained by the adhesive burn-up. As the residence time increases, the temperatures around the weld spot increase, as the temperature curves in Figure 6 show. In addition, the temperature curve at the weld spot (see Figure 2) clearly shows that the specimens experience a higher heat input at $6 \mathrm{~s}$ residence time. At a residence time of $0 \mathrm{~s}$, the lowest heat input occurs, which leads to the lowest weld spot strength but highest FSSBW joint strength, since the material is not sufficiently plasticized but hardly causes any adhesive burn-off, which is why the joint strength is based almost exclusively on the high adhesive strength. The hypothesis: "High weld spot strengths without strength-reducing adhesive burn-off can be achieved by heat-reduced (and economical) design of the process variables" can only be confirmed to a limited extent. For the formation of a welding spot with high strength, a certain residence time is necessary at this sheet thickness in order to sufficiently plastify the material. However, adhesive burn-off cannot be completely avoided for this reason. The welding parameters of test series 6 (Table 4, residence time $2 \mathrm{~s}$ ) offer a compromise between weld spot strength, maximum tensile force, and high plastic elongation. The specimens are characterized by a good weld spot formation, which enables a high plastic elongation, and a justifiable heat input, which causes damage to the adhesive layer but nevertheless allows high maximum tensile shear forces $(22.5 \mathrm{kN})$. Of course, these characteristics have to be adapted to the respective application. For car body components where the material EN AW 6082-T6 is used, a high plastic elongation is advantageous because the impact energy is absorbed more efficiently and a lower change in acceleration occurs. If, however, the maximum tensile force is the decisive parameter, short residence times should be used in order to keep the damage to the adhesive layer as low as possible.

Even though no higher static strengths could be achieved with this hybrid process, it is not unlikely that this hybrid connection will be superior to the individual processes under long-term static or oscillating loads. In addition, the adhesive layer can protect the joint gap from corrosion.

\section{Conclusions}

Regarding the FSSBW, it can be said that the adhesive and the glass beads have very little influence on the formation of the joint. The use of glass beads in the FSSBW is recommended because less adhesive is displaced from the joining area, which increases the joint strength. The goal of obtaining high weld spot strengths without strength-reducing adhesive burn-off could not be achieved, since a certain residence time is necessary to form a weld spot with high strength at this sheet thickness to sufficiently plasticize the material. Adhesive burn-up cannot be completely avoided. For this reason, it is necessary to weigh up which characteristics are required for the specific application and adjust the welding parameters accordingly. For car body components, where the material EN AW 6082-T6 is used, a high plastic elongation is advantageous, since the impact energy is absorbed more efficiently and a lower change in acceleration occurs. The welding parameters of the test series (Table 4, residence time $2 \mathrm{~s}$ ) offer a compromise between weld spot strength, maximum tensile force, and plastic elongation. The specimens are characterized by a good weld spot formation and a justifiable heat input, which causes damage to the adhesive layer but nevertheless enables high maximum tensile shear forces $(22.5 \mathrm{kN})$. The failure of the weld spot is delayed by the failure of the adhesive layer. If, however, the maximum tensile force is the decisive factor, then short residence times should be used in order to keep the damage to the adhesive layer as low as possible, which at the same time, reduces the elongation at break and the weld spot strength.

Even if no higher static strengths could be achieved for this material-adhesive combination with the FSSBW, it is not probable that this hybrid joint will be superior to the individual processes under 
long-term static loading or oscillating loading. Therefore, on the one hand, vibration tests should be carried out and on the other hand, the specimens should be subjected to a climate change load in order to draw conclusions about the component service life.

Author Contributions: Conceptualization, M.H.; methodology, M.H. and A.F.; software, A.F.; validation, M.H. and A.F.; formal analysis, A.F.; investigation, M.H. and A.F.; resources, M.H. and S.B.; data curation, A.F.; writing-original draft preparation, M.H.; writing—review and editing, M.H. and S.B.; visualization, M.H. and A.F.; supervision, M.H. and S.B.; project administration, M.H. and S.B.; funding acquisition, S.B.

Funding: This research was funded by the Federal Ministry of Economics and Energy as the funding agency, the German Association for Welding and Allied Processes and the Federation of Industrial Research Associations as the project executing agency.

Acknowledgments: Special thanks to Ghazal Moeini for the review of the work and the discussions.

Conflicts of Interest: The authors declare no conflict of interest.

\section{References}

1. Brockmann, W.; Geiß, P.L.; Klingenberg, J.; Schröder, B. Klebtechnik. Klebstoffe, Anwendungen und Verfahren; WILEY-VCH: Weinheim, Germany, 2005; ISBN 9783527310913.

2. Silva, L.F.M.d.; Pirondi, A.; Öchsner, A. Hybrid Adhesive Joints; Springer-Verlag Berlin Heidelberg: Berlin/Heidelberg, Germany, 2011; ISBN 9783642166228.

3. Zhang, H. Resistance Welding. Fundamentals and applications; CRC Press: Boca Raton, FL, USA, 2017; ISBN 9781138075245.

4. Liu, H.J.; Fujii, H.; Maeda, M.; Nogi, K. Tensile properties and fracture locations of friction-stir-welded joints of 2017-T351 aluminum alloy. J. Mater. Process. Technol. 2003, 142, 692-696. [CrossRef]

5. Hahn, O.; Kunze, S. Beitrag zur Erhöhung der Prozesssicherheit beim Punktschweißen und Punktschweißkleben von Aluminiumkarosseriewerkstoffen; Shaker: Aachen, Germany, 2014; ISBN 9783844024562.

6. Ostermann, F. Anwendungstechnologie Aluminium; Springer Berlin Heidelberg: Berlin/Heidelberg, Germany, 2014; ISBN 9783662438060.

7. Henkel Adhesive Technologies. Terokal 5089V3.doc. Available online: http://deweb02.henkel.com/technologies\% 5Csurface_technologies\%5Cjsohnius.nsf/webviewde/04492032A2058C07C12574DB002C3713/\$File/Terokal+ 5089V3.pdf?OpenElement (accessed on 23 April 2019).

8. Chowdhury, S.H.; Chen, D.L.; Bhole, S.D.; Cao, X.; Wanjara, P. Lap shear strength and fatigue behavior of friction stir spot welded dissimilar magnesium-to-aluminum joints with adhesive. Mater. Sci. Eng. A 2013, 562, 53-60. [CrossRef]

9. Ding, C.G.; Ni, Y.Q.; Guo, C.J.; Quan, G.F. Study on Microstructure and Performance of Bonding-FSSW Hybrid Joints of AZ31 Magnesium Alloy. Adv. Mater. Res. 2011, 295-297, 1915-1918. [CrossRef]

10. Ding, C.G.; Ni, Y.Q.; Guo, C.J.; Quan, G.F.; Ge, J.P. Study on Procedure of Bonding-FSSW Hybrid Joints of AZ31 Magnesium Alloy. Adv. Mater. Res. 2011, 314-316, 953-956. [CrossRef]

11. Hesse, W. Aluminium-Werkstoff-Datenblätter, Deutsch, 7th ed.; Beuth Verlag GmbH: Berlin, Germany, 2016; ISBN 9783410268758.

12. DIN EN 573-3:2013-12. Aluminium und Aluminiumlegierungen_-Chemische Zusammensetzung und Form von Halbzeug_Teil_3: Chemische Zusammensetzung und Erzeugnisformen; Beuth Verlag GmbH: Berlin, Germany, 2013.

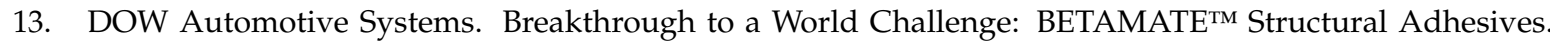
Available online: https://www.dupont.com/content/dam/Dupont2.0/Products/transportation/Literature/TDS/ 299-52351.pdf (accessed on 23 April 2019).

(C) 2019 by the authors. Licensee MDPI, Basel, Switzerland. This article is an open access article distributed under the terms and conditions of the Creative Commons Attribution (CC BY) license (http://creativecommons.org/licenses/by/4.0/). 